\title{
A Prospective Randomized Study on Dietary Predictor of Anaemia Among Children Aged 6 Months to 3 Years
}

\author{
Srikrishna Surampudi ${ }^{\circledR 1}$, K. Muralidhar ${ }^{\circledR 2}$ \\ ${ }^{1}$ Associate Professor, Department of Pediatrics, Apollo institute of medical sciences, Hyderabad, Telangana, India, ${ }^{2}$ Associate Professor, Department of Pediatrics, \\ Kamineni institute of medical sciences, Narketpally, Telangana, India.
}

\section{Abstract}

Background: The present study aimed to record anemia and predictor of anemia in 6 months to 3 years children. Subjects and Methods: The present study was conducted on 280 children age ranged 6 months -3 years of both genders. Children with Hb level $<11$ g/dL were considered anemic, and graded as mild (10-10.9 g/dL), moderate (7-9.9 g/dL), and severe ( $<7 \mathrm{~g} / \mathrm{dL})$. Results: There were 150 male and $130 \mathrm{female}$ children and anemia was seen in 56 male and 70 female children. Anemia was detected in 25 children age ranged 6-12 months, 45 in age group 1-2 years and 56 in $2-3$ years. 85 anemic children were $<2.5 \mathrm{kgs}$ at birth whereas 41 were $>2.5 \mathrm{kgs}$ at birth. 68 were not breastfed while 58 were on exclusive breastfeed. Conclusion: Authors found that low birth weight, female gender, not on breastfeed, vegetables and meat non consumers are determinants of anaemia in children.

Keywords: Anaemia, Breastfeed, Children

Corresponding Author: K. Muralidhar, Associate Professor, Department of Pediatrics, Kamineni institute of medical sciences, Narketpally, Telangana, India.

E-mail: kmuralidhar1963@gmail.com

Received: 02 December 2019

Revised: 25 January 2020

Accepted: 03 February 2020

Published: 28 December 2020

\section{Introduction}

Childhood anemia is a condition where a child has an insufficient hemoglobin $(\mathrm{Hb})$ level to provide adequate oxygen to the body tissues. For children between 6 and 59 months (generally referred to as under-fives), the threshold $\mathrm{Hb}$ level for being nonanemic is 11.0 grams per deciliter $(\mathrm{g} / \mathrm{dL})$. Anemia has numerous potential etiologies. Followed by acute blood loss and heredity or acquired diseases, the most common cause of anemia in young children is low consumption and absorption of iron-rich foods. ${ }^{[1]}$

Iron-deficiency anemia (IDA) is associated with poorer cognitive and neurologic function with predicted long-term health and economic consequences and is a major contributor to the estimated years lived with a disability in children and adolescents. ${ }^{[2]}$ Pregnant and lactating women and under-five children are the most vulnerable social groups to micronutrient deficiencies due to their increased needs for vitamins and minerals. Along with this greater need comes a higher consequence due to lesser reserves. The literature is replete with nutrition interventions, which clearly reveal the "oneoff," cross sectional nature of most interventions. ${ }^{[3]}$
The etiology of anemia is complex and context-dependent and likely differs between mild and severe anemia. ${ }^{[4]}$ Various conceptual models have been developed to illustrate the pathways between proximal and distal determinants of anemia including a framework that is specific to the Biomarkers Reflecting Inflammation and Nutritional Determinants of Anemia (BRINDA) project. Many potential causes of anemia are biologically interrelated, such as infections and nutritional status, and may also be driven by the same environmental and household characteristics, such as low socioeconomic status (SES), sanitation, and education. ${ }^{[5]}$ The present study aimed to record anemia and predictor of anemia in 6 month to 3 years children.

\section{Subjects and Methods}

The present study was conducted in the department of Pediatrics. It comprised of 280 children age ranged 6 months to 3 years of both genders. All parents of children were informed regarding the study and their written consent was obtained. Ethical clearance was taken before starting the study. 
Demographic profile of children such as name, age, gender etc. was recorded. Socioeconomic and demographic characteristics of parents/family, including education level, marital status and occupation were recorded. Children were screened for anemia using the HemoCue (HemoCue ${ }^{\circledR} \mathrm{Hb} 201+$ ) photometer. Safety lancets were used to obtain the finger prick blood, which was collected in the microcuvettes. Alcohol swabs were used to clean the fingers before pricking. The first drop of blood was wiped off with a cotton wool, while the second drop was collected using a microcuvette. The blood sample in the microcuvette was loaded in the calibrated HemoCue ${ }^{\circledR}$ photometer and $\mathrm{Hb}$ concentration read to the nearest $0.1 \mathrm{~g} / \mathrm{dL}$. Children with $\mathrm{Hb}$ level $<11 \mathrm{~g} / \mathrm{dL}$ were considered anemic, and graded as mild (10-10.9 g/dL), moderate (7-9.9 g/dL), and severe $(<7 \mathrm{~g} / \mathrm{dL})$. Analysis of data was done using the Statistical Package for Social Sciences. P value less than 0.05 was considered significant.

\section{Results}

\begin{tabular}{lll}
\hline \multicolumn{2}{l}{ Table 1: Distribution of children } & \\
\hline Parameters & Number & Anaemia \\
\hline $\begin{array}{l}\text { Gender } \\
\text { Male }\end{array}$ & 150 & 56 \\
\hline Female & 130 & 70 \\
\hline Age group (Years) & & \\
\hline 6- 12 months & 70 & 25 \\
1- 2 years & 90 & 45 \\
\hline 2-3 years & 120 & 56 \\
\hline Birth weight (Kgs) & & \\
\hline 2.5 kgs & 135 & 41 \\
\hline 2.5 kgs & 145 & 85 \\
\hline Exclusive breastfeed & \\
\hline Yes & 155 & 58 \\
\hline No & 125 & 68 \\
\hline
\end{tabular}

[Table $1 \&$ Figure 1] shows that there were 150 male and 130 female children and anemia was seen in 56 male and 70 female children. Anemia was detected in 25 children age ranged 612 months, 45 in age group 1-2 years and 56 in 2-3 years. 85 anemic children were $<2.5 \mathrm{kgs}$ whereas 41 were $>2.5 \mathrm{kgs} .68$ were not breastfed while 58 were on exclusive breastfeed.

[Table 2] shows that determinants of anemia were low birth weight, female gender, children not on breastfeeding, advanced age group and meat non consumers, vegetables non consumers $(\mathrm{P}<0.05)$.

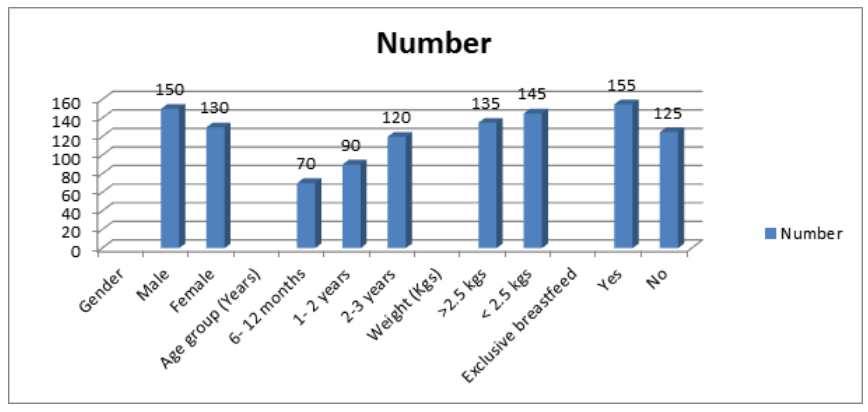

Figure 1: Distribution of children

\section{Discussion}

Anemia has numerous potential etiologies. Followed by acute blood loss and heredity or acquired diseases, the most common cause of anemia in young children is low consumption and absorption of iron-rich foods (ie, meat and meat products). ${ }^{6]}$ These conditions most often lead to iron deficiency anemia, which accounts for approximately half of all anemia cases globally, with under-five children and women being the most affected. ${ }^{[7]}$ Although relevant across the life span, anemia in under-five children is a special case given its significance to underpinning a range of morbidities and mortality within this population subset. Not only are these patterns concerning due to their highly preventable and treatable nature, but they also project potential long-term individual and social consequences. ${ }^{[8]}$ At the individual level, childhood anemia contributes to poor motor and cognitive development, poor school performance, as well as increased morbidity and mortality. At the societal level, there are strong indicators that anemia impacts on the socioeconomic well-being and productivity of a country. Globally, data indicate that $43 \%$ of under-five children were anemic in 2011, with prevalence in the developing world, specifically South Asia and East Africa, being 58\% and 55\%, respectively. ${ }^{[9]}$ The present study aimed to record anemia and predictor of anemia in 6 months to 3 years children.

In this study, there were 150 male and 130 female children and anemia was seen in 56 male and 70 female children. Anemia was detected in 25 children age ranged 6-12 months, 45 in age group 1-2 years and 56 in 2-3 years. 85 anemic children were $<2.5 \mathrm{kgs}$ at birth whereas 41 were $>2.5 \mathrm{kgs}$ at birth. 68 were not breastfed while 58 were on exclusive breastfeed.

Kejo et al, ${ }^{[10]}$ found that prevalence rate of anemia among under-fives was found to be $84.6 \%(n=369)$. Multivariable logistic regression identified the following predictors of anemia; low birth weight, not consuming meat, not consuming vegetables, drinking milk and drinking tea. It was concluded that low birth weight and dietary factors (ie, low or nonconsumption of iron-rich foods like meat, vegetables, and fruits) 
Table 2: Determinants of anaemia

\begin{tabular}{|c|c|c|c|}
\hline Gender & Number & COR & P-value \\
\hline \multicolumn{4}{|c|}{ Age group (Years) } \\
\hline 6- 12 months & 25 & 1 & 0.71 \\
\hline $1-2$ years & 45 & 1.2 & \\
\hline 2-3 years & 56 & 0.8 & \\
\hline \multicolumn{4}{|l|}{ Weight (Kgs) } \\
\hline$>2.5 \mathrm{kgs}$ & 41 & 1 & 0.01 \\
\hline$<2.5 \mathrm{kgs}$ & 85 & 2.3 & \\
\hline \multicolumn{4}{|l|}{ Meat } \\
\hline Consumed & 50 & 8.0 & 0.01 \\
\hline Not consumed & 76 & 8.5 & \\
\hline \multicolumn{4}{|l|}{ Gender } \\
\hline Male & 56 & 1 & 0.05 \\
\hline Female & 70 & 5.2 & \\
\hline \multicolumn{4}{|c|}{ Exclusive breastfeed } \\
\hline Yes & 58 & 2 & 0.01 \\
\hline No & 68 & 5.1 & \\
\hline \multicolumn{4}{|l|}{ Vegetables } \\
\hline Consumed & 68 & 1 & 0.01 \\
\hline Not consumed & 58 & 4.2 & \\
\hline
\end{tabular}

were predictors of anemia among under-five children living in this rural setting. Community education on exclusive breastfeeding and introduction of complementary foods should be improved. Mothers and caretakers should be educated about nutrition, in general, as well as potential use of micronutrient powder to improve the nutritional quality of complementary foods.

We found that determinants of anemia were low birth weight, female gender, not breastfeeding, age group and meat not consumers $(\mathrm{P}<0.05)$. According to Heinrichs et al, ${ }^{[11]}$ a total of 7,324 children aged 6-23 months were included in the analysis, with prevalences of anaemia being $71 \%$ in $2005,61 \%$ in 2011 and $72 \%$ in 2016 . The following determinants were significantly associated with childhood anaemia throughout the entire period: children younger than 1 year, anaemic mothers and those growing up in pastoralist regions. Risk factors such as diet and infections were consistently not significantly associated with anaemia. Given the tremendous adverse health effects of anaemia in young children, urgent action is needed. Hence, this study recommends nationwide multisectoral interventions targeting pastoralist regions, maternal and child health, screening and treatment of risk groups that could reduce the prevalence of anaemia.

Dey et al, ${ }^{[12]}$ found that the mean haemoglobin concentration in children aged 0-6 year(s) was found to be $11.85 \mathrm{~g} / \mathrm{dL}$, with a standard deviation of $5.61 \mathrm{~g} / \mathrm{dL}$. The multiple logistic regression analysis showed that rural children were at greater risk of severe and moderate anaemia. All types of anaemia (severe, moderate, and mild) were more prevalent among Hindu children and then among children of other religions whereas moderate and mild anaemia were more prevalent among Muslim children. The fecundity of the mother was found to have significant effect on anaemia. Women with multiple children were prone to greater risk of anaemia. The multiple logistic regression analysis also confirmed that children of literate mothers were comparatively at lesser risk of severe anaemia. Mother's age at marriage had a significant effect on anaemia of their children as well.

The limitation of the study is small sample size.

\section{Conclusion}

Authors found that low birth weight, female gender, not on breastfeed, vegetables and meat non consumers are determinants of anaemia in children.

\section{References}

1. Abbaspour N, Hurrell R, Kelishadi R. Review on iron and its importance for human health. J Res Med Sci. 2014;19(2):164- 
174.

2. Miller JL. Iron Deficiency Anemia: A Common and Curable Disease. Cold Spring Harb Perspect Med. 2013;13(7):a011866. Available from: https://dx.doi.org/10.1101/cshperspect.a011866.

3. Gernand AD, Schulze KJ, Stewart CP, West KP, Christian $P$. Micronutrient deficiencies in pregnancy worldwide: health effects and prevention. Nat Rev Endocrinol. 2016;12(5):274 289. Available from: https://dx.doi.org/10.1038/nrendo.2016. 37.

4. Kounnavong S, Sunahara T, Mascie-Taylor CGN, Hashizume M, Okumura J, Moji K, et al. Effect of daily versus weekly home fortification with multiple micronutrient powder on haemoglobin concentration of young children in a rural area, Lao People's Democratic Republic: a randomised trial. Nutr J. 2011;10:129. Available from: https://doi.org/10.1186/14752891-10-129.

5. Stevens GA, Finucane MM, De-Regil LM, Paciorek CJ, Flaxman SR, Branca F, et al. Global, regional, and national trends in haemoglobin concentration and prevalence of total and severe anaemia in children and pregnant and non-pregnant women for 1995-2011: a systematic analysis of population-representative data. The Lancet Global Health. 2013;1(1):e16-e25. Available from: https://dx.doi.org/10.1016/s2214-109x(13)70001-9. doi:10.1016/s2214-109x(13)70001-9.

6. Foote EM, Suchdev PS, Williams TN, Sadumah I, Sullivan KM, Oremo J, et al. Determinants of Anemia among Preschool Children in Rural, Western Kenya. Am J Trop Med Hyg. 2013;88(4):757-764. Available from: https://dx.doi.org/10. 4269/ajtmh.12-0560.

7. Heckman J, Samie A, Bessong P, Ntsieni M, Hamandi H, Kohler M. Anaemia among clinically well under-fives attending a community health centre in Venda, Limpopo Province. S Afr Med J. 2010;100(7):445. Available from: https://dx.doi.org/10.7196/samj.3579.

8. Tatala S, Svanberg U, Mduma B. Low dietary iron availability is a major cause of anemia: a nutrition survey in the Lindi
District of Tanzania. Am J Clin Nutr. 1998;68(1):171-178. Available from: https://dx.doi.org/10.1093/ajcn/68.1.171.

9. Kishawi RRE, Soo KL, Abed YA, Muda WAMW. Anemia among children aged 2-5 years in the Gaza Strip- Palestinian: a cross sectional study. BMC Public Health. 2015;15:319. Available from: https://dx.doi.org/10.1186/s12889-015-16522.

10. Kejo D, Petrucka P, Martin H, Kimanya M, Mosha T. Prevalence and predictors of anemia among children under 5 years of age in Arusha District, Tanzania. Pediatric Health Med Ther. 2018;9:9-15. Available from: https://dx.doi.org/10.2147/ phmt.s148515.

11. Heinrichs H, Endris BS, Dejene T, Dinant GJ, Spigt M. Anaemia and its determinants among young children aged 623 months in Ethiopia. Maternal \& Child Nutrition. 2020;p. 13082. Available from: https://doi.org/10.1111/mcn.13082.

12. Dey S, Goswami S, Dey T. Identifying Predictors of Childhood Anaemia in North-East India. J Health Popul Nutr . 2014;31(4):462-470. Available from: https://dx.doi.org/10. 3329/jhpn.v31i4.20001.

Copyright: (C) the author(s), 2020. It is an open-access article distributed under the terms of the Creative Commons Attribution License (CC BY 4.0), which permits authors to retain ownership of the copyright for their content, and allow anyone to download, reuse, reprint, modify, distribute and/or copy the content as long as the original authors and source are cited.

How to cite this article: Surampudi S, Muralidhar K. A Prospective Randomized Study on Dietary Predictor of Anaemia Among Children Aged 6 Months to 3 Years. Asian J. Clin. Pediatr. Neonatol. 2020;8(4):1-4.

DOI: dx.doi.org/10.47009/ajcpn.2020.8.4.1

Source of Support: Nil, Conflict of Interest: None declared. 